\title{
Evaluation of Auditory Attention and Memory Skills in Autistic Children after Hyperbaric 02 Treatment
}

\author{
Original Reham Mamdouh Lasheen', Mohamed Hassan Abu-Zaid ${ }^{2}$ and Samar Abd AlHamed \\ Article \\ Tabra ${ }^{2}$ \\ ${ }^{1}$ Audiology department, ${ }^{2}$ Rheumatology and rehabilitation department, Tanta University, \\ Tanta, Egypt
}

\begin{abstract}
Introduction: The children with autism often exhibit abnormalities in auditory central processing including both auditory attention and auditory memory.

Objective: The aim of this research was to determine the effectiveness of the hyperbaric oxygen therapy in improving auditory attention and auditory memory.

Method: The study included 20 children with autism and 20 normally developed children as the control group. The children with autism were evaluated before and after treatment with hyperbaric oxygen using audirory P300 and MMN to evaluate both auditory attention and auditory memory.

Results: There was a statistically significant difference of the auditory P300 and MMN latencies in the autistic children before and after treatment with hyperbaric oxygen therapy. There was a decrease of the P300 and MMN latencies, after the hyperbaric oxygen therapy.

Conclusion: The children with autism showed improvement in both auditory attention and auditory memory after hyperbaric oxygen therapy.
\end{abstract}

Key Words: Attention, autistic disorder, cognition, hyperbaric oxygenation, memory.

Received: 22 March 2019, Accepted: 18 May 2019

Corresponding Author: Reham Mamdouh Lasheen, PhD, Audiovestibular unit, faculty of medicine, Tanta University, Tanta, Egypt, Tel.: +2 01224882153, E-mail: doctor_r12006@yahoo.com

ISSN: 2090-0740, July 2019 Vol.20, No.2

\section{INTRODUCTION:}

Autism is a pervasive developmental disorder characterized by deficits in socialization, communication, and adaptive functioning with restrictive and repetitive behaviors $^{[1-3]}$. In addition, children with autism often exhibit abnormalities in auditory processing including both auditory attention and memory ${ }^{[4,5]}$.

Hyperbaric oxygen therapy (HBOT) involves inhaling up to $100 \%$ oxygen at a pressure greater than one atmosphere (atm) in a pressurized chamber. HBOT is indicated in several clinical disorders include healing of wounds, diabetic foot $^{[6]}$, arterial gas embolism, decompression sickness and carbon monoxide poisoning ${ }^{[7]}$. Higher pressure HBOT increases the plasma oxygen content and body tissues and may normalize oxygen levels in ischemic tissue $\mathrm{e}^{[8]}$.

Hyperbaric oxygen may improve the cerebral hypoperfusion and mitochondrial dysfunction in children with autism, it decreases brain inflammation as well as oxidative stress in autism ${ }^{[9]}$. Hyperbaric oxygen therapy does not exacerbate the increased oxidative stress in autism. Moreover, it does not affect plasma oxidized glutathione level ${ }^{[10,11]}$.

The use of oxygen appears to enhance neurological function. Oxygen administration in healthy young adults enhances cognitive performance, including improved performance on cognitive function, attention, reaction times, and word recall ${ }^{[12]}$.

Our work was designed to evaluate the improvement of both auditory attention and memory in children with autism after treatment with hyperbaric oxygen, using auditory P300 and mismatch negativity (MMN) tests.

\section{SUBJECTS AND METHOD:}

\section{A. Subjects:}

This study included 20 children with autism and 20 normally developed children as controls. All participants had normal peripheral hearing evidenced by the audiogram (Fig. 1). This study was conducted in Tanta University hospital between February to October 2017. 


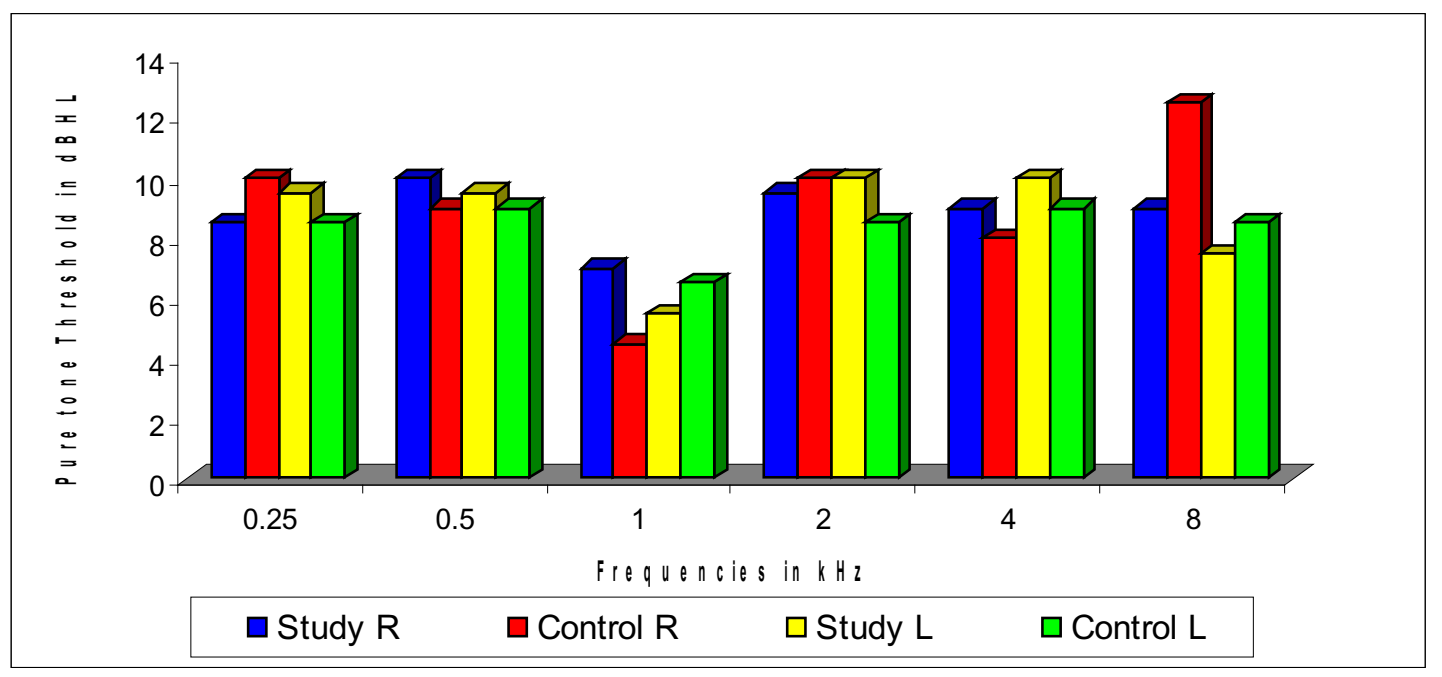

R: right ear, L: left ear

Fig. 1: graph represent pure tone threshold in the control and the study group in right and left ear. It shows normal peripheral hearing in both groups.

The autism group (I) consisted of 20 children of high-functioning autism. Their IQ was more than 70 and Childhood Autism Rating Scale (CARS) less than 33. The study group had attention and memory affection which diagnosed by Stanford Binet intelligence scale-fifth edition cognitive subtest and confirmed by P300 and MMN tests before hyperbaric oxygen therapy. The age of the study group ranged from 8-14 years with the mean of 10.6 \pm 2.4 . This age group was selected to understand the tests' instructions easier than younger age groups. The control group was chronologically age matched with the study group.

We excluded the children who did not understand the instructions of the tests and children lost in the follow up. We also excluded children suffering from major medical, neurological or psychiatric diseases, abnormal EEG and patients taking drugs that can affect cognitive functions. We excluded cases with persistent dysfunction of the middle ear ventilation (diagnosed clinically and by immittancemetry) as they were contraindicated for the use of HBOT. We excluded children with pneumothorax or emphysema, ruptured tympanic membrane and ejection fraction less than $60 \%$ as these are also contraindications of HBOT. On the other hand, the control group (II) consisted of 20 children with no complaint of any cognitive, developmental disorder or history of special education. Normal auditory attention and memory in the control group was confirmed by Stanford Binet intelligence scalefifth edition cognitive subtest.

The study was approved by the institutional ethics committee in Faculty of Medicine Tanta University and all participants gave informed written consent from their parents before entering the study. All the procedures followed in this study were in accordance with the ethical standards of the responsible committee on human experimentation and with the Helsinki Declaration of 1975 , as revised in 1983 .

\section{B. Method}

i. Detailed personal and medical history.

ii. Basic audiological evaluation by standard pure tone audiometer GSI version 61 audiometer (Viasys- USA) Flow Sensor for VIASYS AVEA Ventilator, New, Original) for pure tone audiometry using headphone TDH 39. Play audiometry by interacoustics (AD226) was done in some cases that were not cooperative in pure tone audiometry. Acoustic immitance measurements (tympanometry/stapedial reflex) by interacoustics AT235H impedance using low frequency $226 \mathrm{~Hz}$ probe tone (Middelfart, Denmark).

iii.Event related potentials (ERPs): elicited by Smart EPs of Intelligent hearing system using ER3A insert phone (HIS, Miami, FL). Electrode montage: high frontal $\mathrm{Fz}$ and one low frontal Fpz for positive electrode and ground electrode, respectively. The last two electrodes were placed on the left and right mastoids (as reference electrodes). All electrodes were connected to the preamplifier of the Smart EP equipment. The case group was assessed by both P300 and MMN pre and forty sessions post intervention of HBOT while the control group was assessed by both tests with no intervention of HBOT:

a. Auditory P300 was recorded using oddball paradigms where in two tone stimuli were presented in a random order, one occurred less frequently than the other (target: $2000 \mathrm{~Hz}$ tone burst with $50 \mathrm{msec}$ rise/fall time and $200 \mathrm{msec}$ plateau.). The child was required to discriminate target (the rare) stimulus 
from the frequent one (standard: $1000 \mathrm{~Hz}$ tone burst) by counting it. The test instructions were simplified as possible to the children. All the children had undergone training on the test before test recording began to assure that they understand the instructions. The probability of target and standard stimuli were 20 and 80 percent respectively at a rate $0.7 / \mathrm{s}$. The total numbers of stimuli were not less than 100 stimuli and not more than 200 stimuli in each run. Stimuli presented monaurally at an intensity of $80 \mathrm{dBnHL}$.

Two parameters of P300 were measured (amplitude $\&$ latency). The amplitude in microvolt $(\mu v)$ was defined as being the potential difference between the baseline and the peak of the positive wave. P300 latency was defined in msec as the period of time between the stimulus onsets and the wave apex.

B. Mismatch Negativity (MMN) was recorded using oddball paradigms in response to tone stimuli; 1200 $\mathrm{Hz}$ tone burst as a target and $1000 \mathrm{~Hz}$ tone burst as a standard. Stimuli presented monaurally at an intensity of $70 \mathrm{dBnHL}$. Polarity of the stimulation was alternating at a rate $1.1 / \mathrm{s}$. Probability of the stimuli $85 \%$ for the standard and $15 \%$ for the target. The children were instructed to lie down calmly and allowed to choose read a story, looking at some interesting pictures or playing with a toy or simple game. At the same time, they were instructed not to concentrate on the presented stimuli.

After finishing the test we detected N100 latency on both standard and deviant traces as the negativity that occur around $100 \mathrm{msec}$. MMN was calculated in the difference wave form. This was done by creating a new destination buffer. Then the trace that occurred in response to the deviant stimulus alone was added to this new buffer. After that, the trace that occurred in response to standard stimulus alone was subtracted from the response to the deviant stimulus. The resulting difference between the standard and deviant stimulus traces represented the MMN responses which were identified visually as the prominent negativity following N100.

Two parameters of MMN were measured (amplitude \& latency). The amplitude in microvolt ( $\mu \mathrm{v})$ was defined as being the potential difference between the baseline and the peak of the negative wave following N100. MMN latency was defined in msec as the period of time between the stimulus onsets and the negative wave apex following N100.

iv. Hyperbaric therapy: (was only applied to the study group) at $1.5 \mathrm{~atm}$ and $100 \%$ oxygen in a monoplace Sechrist 3600E hyperbaric chamber using Sechrist 3600E hyperbaric chamber for hyperbaric therapy. This therapy was given 45 minutes daily for a total of 40 sessions per child.

\section{Statistics:}

Data were analyzed using Statistical Program for Social Science (SPSS) version 20. Quantitative data were expressed as mean \pm standard deviation (SD).

The following tests were done:

- Independent $t$ test for comparison between control and study groups before hyperbaric oxygen therapy

- Dependent t-test was used for comparing between before and after hyperbaric oxygen therapy in the study group

$P$-value $<0.05$ was considered statistically significant

\section{RESULTS}

This study included 40 children with normal peripheral hearing (Fig. 1). Group (I) consisted of 20 children (11 males and 9 females) diagnosed as autistic with attention and memory affection which diagnosed by Stanford Binet intelligence scale-fifth edition cognitive subtest and confirmed by P300 and MMN tests before hyperbaric oxygen therapy.. The control group (II) consisted of 20 children (10 males and 10 females). The age in the study group ranged from 8-14 years with the mean of $10.6 \pm 2.4$. The age of the children in the control group was chronologically matched with the study group. There were no statistically significant differences as regards sex between the two groups $(p>0.05)$.

There were no statistically significant differences between right and left ears as regard latency and amplitude of both P300 and MMN tests in the both groups $(p>0.05)$. So, both ears were considered as one group including 40 ears in the control and the study group in the following tests.

There were statistically significant differences between both groups ( $p<0.05$ ) on comparing P300 and MMN latencies and amplitudes before HBOT; the study group showed delayed latencies and decreased amplitudes for both P300 and MMN (Table 1, Fig. 2,3).

There was a statistically significant decrease $(p<0.05)$ in P300 and MMN latencies in the autistic children after treatment with hyperbaric oxygen therapy. Although, the amplitude of P300 and MMN in the study group was increased after hyperbaric oxygen therapy; it was not statistically significant (Table 2, Fig. 2,3). 
Lasheen et al.

Table 1: Comparison between P300 and MMN latency and amplitude in the control group and the study group before hyperbaric oxygen therapy

\begin{tabular}{|c|c|c|c|c|c|}
\hline & & Group I (patients) & Group II (controls) & T. test & $P$-value \\
\hline \multirow{2}{*}{ P300 Latency (msec) } & Mean \pm SD & $351.46 \pm 31.85$ & $325.04 \pm 28.16$ & \multirow{2}{*}{3.9} & \multirow{2}{*}{$0.0002 *$} \\
\hline & Range & $319: 383$ & $301: 352$ & & \\
\hline \multirow{2}{*}{ P300 amplitude(uv) } & Mean \pm SD & $3.16 \pm 1.57$ & $4.7 \pm 0.94$ & \multirow{2}{*}{-5.26} & \multirow{2}{*}{$<0.0001^{*}$} \\
\hline & Range & $1.5: 4.7$ & $3.8: 5.7$ & & \\
\hline \multirow{2}{*}{ MMN Latency(msec) } & Mean $\pm \mathrm{SD}$ & $239 \pm 18.05$ & $205 \pm 63.37$ & \multirow{2}{*}{3.26} & \multirow{2}{*}{$0.0016^{*}$} \\
\hline & Range & $219: 258$ & $135: 268$ & & \\
\hline \multirow{2}{*}{ MMN Amplitude(uv) } & Mean \pm SD & $1.39 \pm 0.5$ & $2.01 \pm 0.52$ & \multirow{2}{*}{-5.43} & \multirow{2}{*}{$<0.0001^{*}$} \\
\hline & Range & $0.9: 1.9$ & $1.5: 2.6$ & & \\
\hline
\end{tabular}

* Significant $P<0.05$

MMN, mismatch negativity; This table shows the comparison between P300 and MMN latency and amplitude in the control group and the study group before hyperbaric oxygen therapy. There were statistically significant differences between both groups; the study group showed delayed latencies and decreased amplitudes for both P300 and MMN

Table 2: Comparison between P300 and MMN latency and amplitude before and after treatment with hyperbaric oxygen in the study group

\begin{tabular}{|c|c|c|c|c|c|}
\hline & & Before HBOT & After HBOT & T. test & $P$-value \\
\hline \multirow{2}{*}{ P300 Latency (msec) } & Mean \pm SD & $351.46 \pm 31.85$ & $338.6 \pm 19.61$ & \multirow{2}{*}{-2.2} & \multirow{2}{*}{$0.033^{*}$} \\
\hline & Range & $319: 383$ & $311: 342$ & & \\
\hline \multirow{2}{*}{ P300 amplitude(uv) } & Mean \pm SD & $3.16 \pm 1.57$ & $3.9 \pm 1.94$ & \multirow{2}{*}{1.9} & \multirow{2}{*}{0.065} \\
\hline & Range & $1.5: 4.7$ & $2.8: 5.4$ & & \\
\hline \multirow{2}{*}{ MMN Latency(msec) } & Mean \pm SD & $239 \pm 18.05$ & $229.6 \pm 18.05$ & \multirow{2}{*}{-2.33} & \multirow{2}{*}{$0.023 *$} \\
\hline & Range & $219: 258$ & 209:248 & & \\
\hline \multirow{2}{*}{ MMN Amplitude(uv) } & Mean \pm SD & $1.39 \pm 0.5$ & $1.59 \pm 0.41$ & \multirow{2}{*}{1.96} & \multirow{2}{*}{0.054} \\
\hline & Range & $0.9: 1.9$ & $1.3: 2.2$ & & \\
\hline
\end{tabular}

* Significant $P<0.05$

MMN, mismatch negativity; This table shows the comparison between P300 and MMN latency and amplitude before and after treatment with hyperbaric oxygen in the study group. There was a statistically significant decrease $(p<0.05)$ in P300 and MMN latencies in the autistic children after treatment with hyperbaric oxygen therapy.
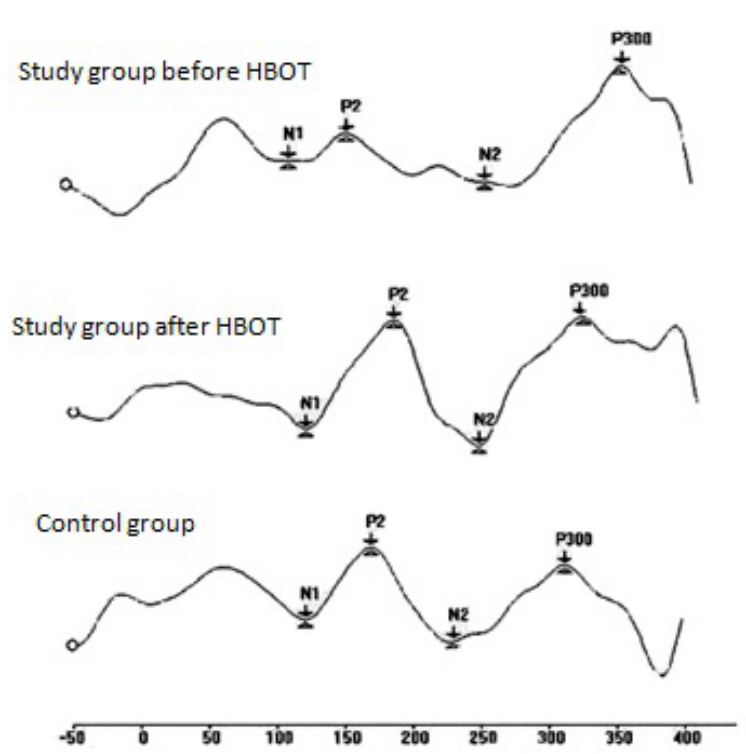

Study group before HBOT

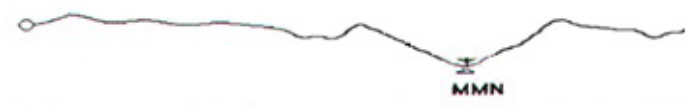

Study group after HBOT

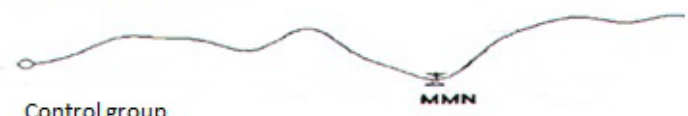

Control group

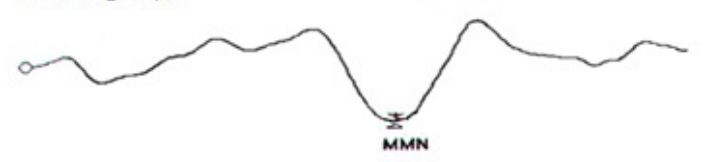

Fig. 3: MMN waves in control group and study group before and after HBOT

Fig. 2: P300 waves in control group and study group before and after HBOT 


\section{DISCUSSION:}

Abnormalities in the auditory processing including both auditory attention and memory usually occur in the autistic children ${ }^{[4,5]}$. Our results showed that the HPOT improved auditory attention and memory in autistic children.

Hyperbaric oxygen treatment (HBOT) is indicated in several clinical disorders include decompression sickness, healing of problem wounds and arterial gas embolism ${ }^{[7]}$. Stoller ${ }^{[13]}$. in his study reported a significant improvement in the IQ of a 15 year old child who had a fetal alcohol syndrome using HBOT at $1.5 \mathrm{~atm} / 100 \%$ oxygen for 73 sessions. Others ${ }^{[14-17]}$. had reported that the HBOT possesses a neuro-protective effect, and can enhance the cognitive functions including the attention and memory. The HBOT may improve some physiological abnormalities of the autistic children including the cerebral hypoperfusion, inflammation, and mitochondrial dysfunction ${ }^{[9]}$.

There are scanty of studies searching for the effect of HBOT on autism and there is a debate if the HBOT increase the oxidative stress via the production of reactive oxygen species or not ${ }^{[18]}$. This may have a special importance especially that some children with autism express evidence of increased oxidative stress including lower serum glutathione levels, ${ }^{[19-21]}$ and decreased the activities of antioxidant enzymes including superoxide dismutase (SOD), glutathione peroxidase, ${ }^{[22]}$ catalase, ${ }^{[23]}$ and paraoxonase (an enzyme that prevents lipid oxidation and also inactivates organophosphate toxins in humans) [24] Some autistic children also demonstrate evidence of increased lipid peroxidation ${ }^{[23,25,26]}$ this includes increased malondialdehyde which is a marker of oxidative stress and lipid peroxidation. ${ }^{[27]}$ Wada K. et al. ${ }^{[28]}$ reported in their study that the oxidative stress can occur with the HBOT but appears to be of a less concern at the hyperbaric pressures under $2.0 \mathrm{~atm}$. On the other hand, other studies ${ }^{[29,30]}$ showed that long-term and repeated administration of the HBOT below $2.0 \mathrm{~atm}$, can actually decreases the oxidative stress by reducing lipid peroxidation, ${ }^{[31]}$ and by up-regulating the activity of antioxidant enzymes including SOD,${ }^{[29,32]}$ glutathione peroxidase, ${ }^{[33]}$ catalase,${ }^{[34]}$ and paraoxonase ${ }^{[31,35]}$.

Our results agreed with Heuser et al. ${ }^{[36]}$ who reported treatment of a four year old child with autism using the hyperbaric oxygen therapy and noticed improvement in the behavior including the memory and the cognitive functions after ten sessions. This child also had marked improvement of the cerebral hypoperfusion as measured by prehyperbaric and post-hyperbaric Single Photon Emission Computed Tomography (SPECT) scans. ${ }^{[37]}$ Shi XY et al..$^{[38]}$ reported clinical improvements in six autistic children by the hyperbaric oxygen therapy. Our results agreed with Rossignol et al..$^{[10]}$, they studied the effects of hyperbaric oxygen therapy on oxidative stress, inflammation, and symptoms in children with autism
From our results, we concluded that HBOT improve auditory attention and memory in cases of autism. We recommend increasing the sample size in the further studies on the effect of hyperbaric oxygen therapy in cases of autism with more number of HBOT sessions.

\section{ACKNOWLEDGEMENT:}

NAD

\section{AUTHORSHIP CONTRIBUTION:}

All authors included in clinical examination, collecting the data, writing and preparation of manuscript.

\section{CONFLICT OF INTEREST:}

None.

\section{FUNDING RESOURCES:}

This research received no specific grant from any funding agency in the public, commercial, or not-for-profit sectors.

\section{REFERENCE}

1. Tager-Flusberg H, Joseph R, Folstein S. Current directions in research on autism. Ment Retard Dev Disabil Res Rev. 2001;7:21-9.

2. Guthrie W, Swineford LB, Nottke C, Wetherby AM. Early diagnosis of autism spectrum disorders: stability and change in clinical diagnosis and symptom presentation. J Child Psychol Psychiatry. 2013; 54:582-90.

3. Shenoy MD, Indla V and Reddy H. Comprehensive Management of Autism: Current Evidence. Indian J Psychol Med. 2017; 39: 727-731.

4. Danesh AA, Kaf WA, Abdelhakiem MK, Danesh $\mathrm{D}$ and Scott J. Auditory Manifestations and Intervention in Children with Autism Spectrum Disorders. Austin J Autism \& Relat Disabil. 2015;1: 1005.

5. Visser E, Zwiers MP, Kan CC, Hoekstra L, Van Opstal AJ, Buitelaar JK. Atypical vertical sound localization and sound-onset sensitivity in people with autism spectrum disorders. J Psychiatry Neurosci. 2013; 38: 120177.

6. Ennis WJ, Huang ET, Gordon H. Impact of Hyperbaric Oxygen on More Advanced Wagner Grades 3 and 4 Diabetic Foot Ulcers: Matching Therapy to Specific Wound Conditions. Adv Wound Care. 2018; 7: 397-407. 
7. Gill AL, Bell CN. Hyperbaric oxygen: its uses, mechanisms of action and outcomes. QJM. 2004;97:385-95.

8. Shandling AH, Ellestad MH, Hart GB, Crump R, Marlow D, Van Natta B, et al. Hyperbaric oxygen and thrombolysis in myocardial infarction: the "HOT MI" pilot study. Am Heart J. 1997; 134:544-50.

9. Rossignol DA. Hyperbaric oxygen therapy might improve certain pathophysiological findings in autism. Med Hypotheses. 2007;68:1208-27.

10. Rossignol DA, Rossignol LW, James SJ, Melnyk $\mathrm{S}$, Mumper E. The effects of hyperbaric oxygen therapy on oxidative stress, inflammation, and symptoms in children with autism: an open-label pilot study. BMC pediatrics. 2007;7:36.

11. Rossignol DA, Rossignol LW. Hyperbaric oxygen therapy may improve symptoms in autistic children. Medical hypotheses. 2006;67:216-28.

12. Moss MC, Scholey AB, Wesnes K. Oxygen administration selectively enhances cognitive performance in healthy young adults: a placebocontrolled double-blind crossover study. Psychopharmacology. 1998;138:27-33.

13. Stoller KP. Quantification of neurocognitive changes before, during, and after hyperbaric oxygen therapy in a case of fetal alcohol syndrome. J Pediatr. 2005;116:e586-91.

14. Harch PG, Andrews SR, Fogarty EF, Amen D, Pezzullo JC, Lucarini J, et al. A phase I study of low-pressure hyperbaric oxygen therapy for blast-induced post-concussion syndrome and post-traumatic stress disorder. J Neurotrauma. 2012;29:168-85.

15. Huang L, Obenaus A. Hyperbaric oxygen therapy for traumatic brain injury. Med gas res. 2011;1:21.

16. Matchett GA, Martin RD, Zhang JH. Hyperbaric oxygen therapy and cerebral ischemia: neuroprotective mechanisms. Neurol Res. 2009;31:114-21.

17. HenningerN, Kuppers-Tiedt L, Sicard KM, Gunther A, Schneider D, Schwab S. Neuroprotective effect of hyperbaric oxygen therapy monitored by MRimaging after embolic stroke in rats. Exp Neurol. 2006;201:316-23.
18. Rossignol DA, Frye RE. A review of research trends in physiological abnormalities in autism spectrum disorders: immune dysregulation, inflammation, oxidative stress, mitochondrial dysfunction and environmental toxicant exposures. Mol Psychiatry. 2011;17:389-401.

19. James SJ, Melnyk S, Jernigan S, Cleves MA, Halsted CH, Wong DH, et al. Metabolic endophenotype and related genotypes are associated with oxidative stress in children with autism. Am J Med Genet. 2006;141b:947-56.

20. Chauhan A, Chauhan V. Oxidative stress in autism. Pathophysiology. 2006;13:171-81.

21. Sakulchit T, Ladish C, Goldman RD. Hyperbaric oxygen therapy for children with autism spectrum disorder. Can Fam Physician. 2017; 63: 446-448.

22. Yorbik O, Sayal A, Akay C, Akbiyik DI, Sohmen $T$. Investigation of antioxidant enzymes in children with autistic disorder. Prostaglandins Leukot Essent Fatty Acids. 2002;67:341-3.

23. Zoroglu SS, Armutcu F, Ozen S, Gurel A, Sivasli E, Yetkin $\mathrm{O}$, et al. Increased oxidative stress and altered activities of erythrocyte free radical scavenging enzymes in autism. Eur Arch Psychiatry Clin Neurosci. 2004;254:143-7.

24. D'Amelio M, Ricci I, Sacco R, Liu X, D'Agruma L, Muscarella LA, et al. Paraoxonase gene variants are associated with autism in North America, but not in Italy: possible regional specificity in gene-environment interactions. Mol Psychiatry. 2005;10:1006-16.

25. Yao Y, Walsh WJ, McGinnis WR, Pratico D. Altered vascular phenotype in autism: correlation with oxidative stress. Arch Neurol. 2006;63:1161-4.

26. Ming X, Stein TP, Brimacombe M, Johnson WG, Lambert GH, Wagner GC. Increased excretion of a lipid peroxidation biomarker in autism. Prostaglandins Leukot Essent Fatty Acids. 2005;73:379-84.

27. Chauhan A, Chauhan V, Brown WT, Cohen I. Oxidative stress in autism: increased lipid peroxidation and reduced serum levels of ceruloplasmin and transferrin--the antioxidant proteins. Life Sci. 2004;75:2539-49. 
28. Wada K, Miyazawa T, Nomura N, Tsuzuki N, Nawashiro H, Shima K. Preferential conditions for and possible mechanisms of induction of ischemic tolerance by repeated hyperbaric oxygenation in gerbil hippocampus. Neurosurgery. 2001; 49:160-6.

29. Ozden TA, Uzun H, Bohloli M, Toklu AS, Paksoy M, Simsek G, et al. The effects of hyperbaric oxygen treatment on oxidant and antioxidants levels during liver regeneration in rats. Tohoku $\mathrm{J}$ Exp Med. 2004;203:253-65.

30. Yasar M, Yildiz S, Mas R, Dundar K, Yildirim A, Korkmaz A, et al. The effect of hyperbaric oxygen treatment on oxidative stress in experimental acute necrotizing pancreatitis. Physiol Res. 2003; 52:111-6.

31. Kudchodkar BJ, Wilson J, Lacko A, Dory L. Hyperbaric oxygen reduces the progression and accelerates the regression of atherosclerosis in rabbits. Arterioscler Thromb Vasc Biol. 2000;20:1637-43.

32. Gregorevic P, Lynch GS, Williams DA. Hyperbaric oxygen modulates antioxidant enzyme activity in rat skeletal muscles. Eur J Appl Physiol. 2001;86:24-7.

33. Gulec B, Yasar M, Yildiz S, Oter S, Akay C, Deveci $\mathrm{S}$, et al. Effect of hyperbaric oxygen on experimental acute distal colitis. Physiol Res. 2004;53:493-9.
34. Nie H, Xiong L, Lao N, Chen S, Xu N, Zhu Z. Hyperbaric oxygen preconditioning induces tolerance against spinal cord ischemia by upregulation of antioxidant enzymes in rabbits. $\mathrm{J}$ Cereb Blood Flow Metab. 2006;26:666-74.

35. Sharifi M, Fares W, Abdel-Karim I, Koch JM, Sopko J, Adler D. Usefulness of hyperbaric oxygen therapy to inhibit restenosis after percutaneous coronary intervention for acute myocardial infarction or unstable angina pectoris. Am J Cardiol. 2004;93:1533-5.

36. Heuser G HS, Rodelander D, Aguilera O, Uszler M. Treatment of neurologically impaired adults and children with "mild" hyperbaric oxygenation (1.3 ATM and $24 \%$ oxygen). In: JT J, editor. Hyperbaric oxygenation for cerebral palsy and the brain-injured child. Arizona: Flagstaff; 2002. p. 109-16.

37. Golden ZL, Neubauer R, Golden CJ, Greene L, Marsh J, Mleko A. Improvement in cerebral metabolism in chronic brain injury after hyperbaric oxygen therapy. Int J Neurosci. 2002;112:119-31.

38. Shi XY, Tang ZQ, Sun D, He XJ. Evaluation of hyperbaric oxygen treatment of neuropsychiatric disorders following traumatic brain injury. Chin Med J. 2006;119:1978-82. 